\title{
Contribution of local and remote anthropogenic aerosols to intensification of a record-breaking torrential rainfall event in Guangdong Province
}

Zhen Liu ${ }^{1,2}$, Yi Ming ${ }^{3}$, Chun Zhao ${ }^{4}$, Ngar Cheung Lau ${ }^{5,2,1}$, Jianping Guo ${ }^{6}$, Steve Hung Lam Yim ${ }^{5,2,1}$

$5 \quad{ }^{1}$ Institute of Space and Earth Information Science, The Chinese University of Hong Kong, Hong Kong, China ${ }^{2}$ Institute of Environment, Energy and Sustainability, The Chinese University of Hong Kong, Sha Tin, N.T., Hong Kong ${ }^{3}$ Geophysical Fluid Dynamics Laboratory/NOAA, Princeton, New Jersey, USA

${ }^{4}$ School of Earth and Space Sciences, University of Science and Technology of China, Hefei, Anhui, China

${ }^{5}$ Department of Geography and Resource Management, The Chinese University of Hong Kong, Sha Tin, N.T., Hong Kong

$10{ }^{6}$ State Key Laboratory of Severe Weather, Chinese Academy of Meteorological Sciences, Beijing 100081, China

Correspondence to: Steve H.L. Yim (steveyim@cuhk.edu.hk)

(a) Terrain Height

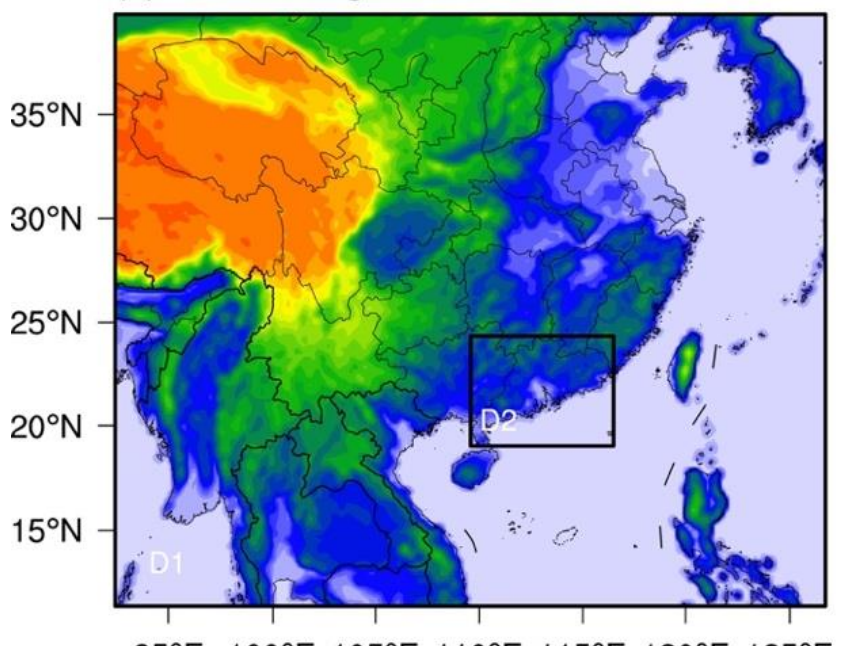

$95^{\circ} \mathrm{E} 100^{\circ} \mathrm{E} 105^{\circ} \mathrm{E} 110^{\circ} \mathrm{E} 115^{\circ} \mathrm{E} 120^{\circ} \mathrm{E} 125^{\circ} \mathrm{E}$ (b) $\mathrm{PM}_{2.5}$ \& 925-hPa Wind

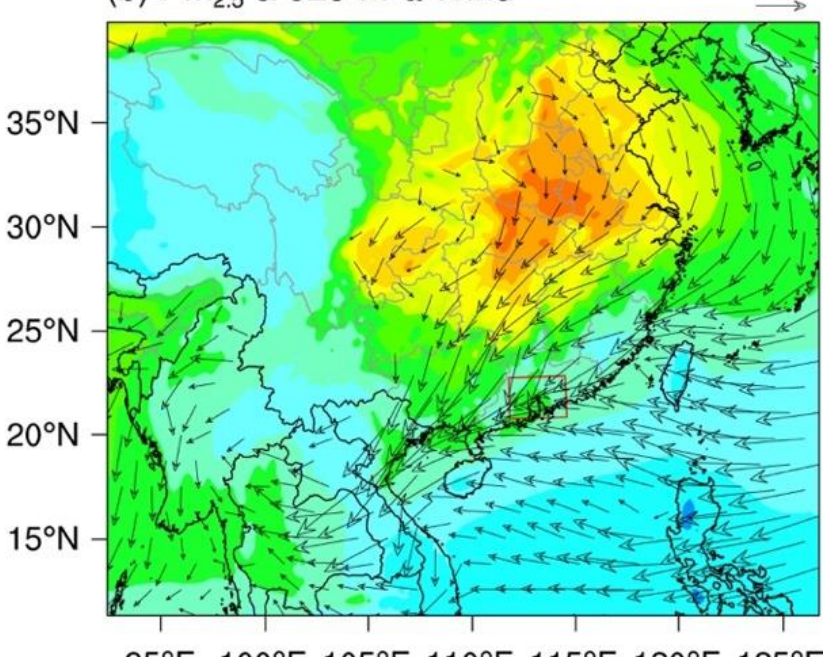

$95^{\circ} \mathrm{E} 100^{\circ} \mathrm{E} 105^{\circ} \mathrm{E} 110^{\circ} \mathrm{E} 115^{\circ} \mathrm{E} 120^{\circ} \mathrm{E} 125^{\circ} \mathrm{E}$

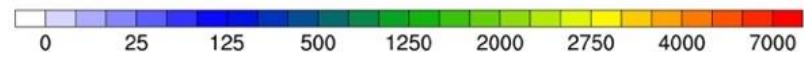

$10 \quad 50 \quad 100 \quad 150 \quad 200 \quad 300 \quad 4005006008001000120015002000$

Figure S1. (a) WRF-Chem model two-nested domains with resolutions of $20 \mathrm{~km}$ and $4 \mathrm{~km}$ for domain 1 (D1) and domain 2 (D2), respectively. Shading represents terrain height (unit: $\mathrm{m}$ ). (b) Spatial distribution of 3-day averaged column-integrated PM 2.5 concentrations (shading; unit: $\mu \mathrm{g} \mathrm{m}^{-2}$ ) and 925-hPa wind (vector; unit: $\mathrm{m} \mathrm{s}^{-1}$ ) during December 14-16, 2013, in control run. The red box denotes the analysis region. 


\section{Precipitation}

(a) CTL-CLEAN

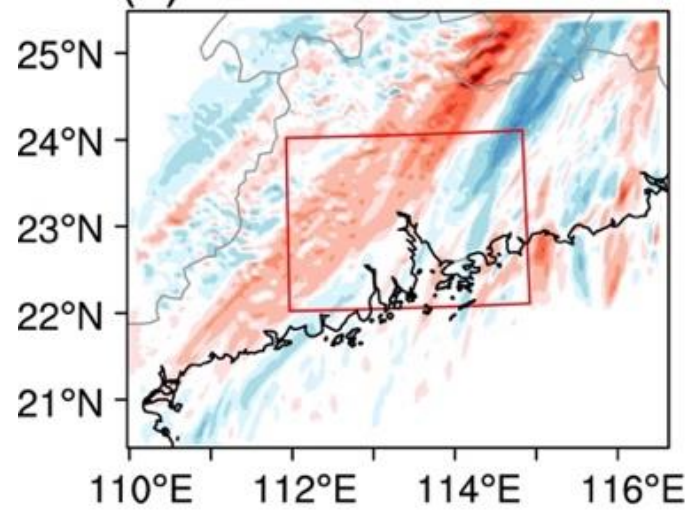

(b) CTL-ARIoff

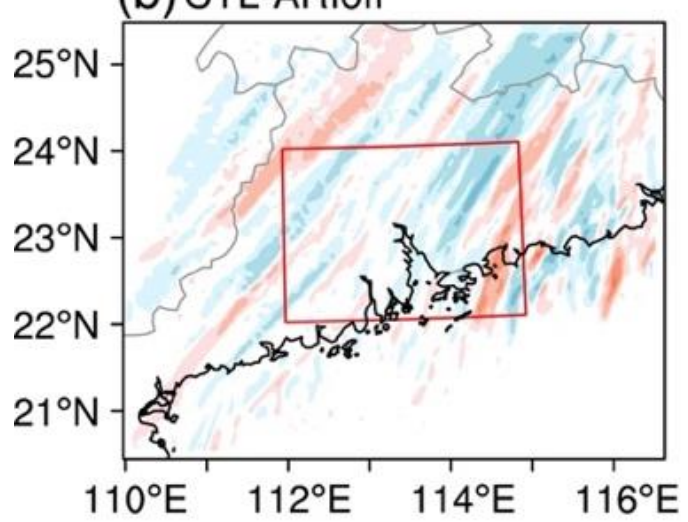

(c) ARIoff-CLEAN

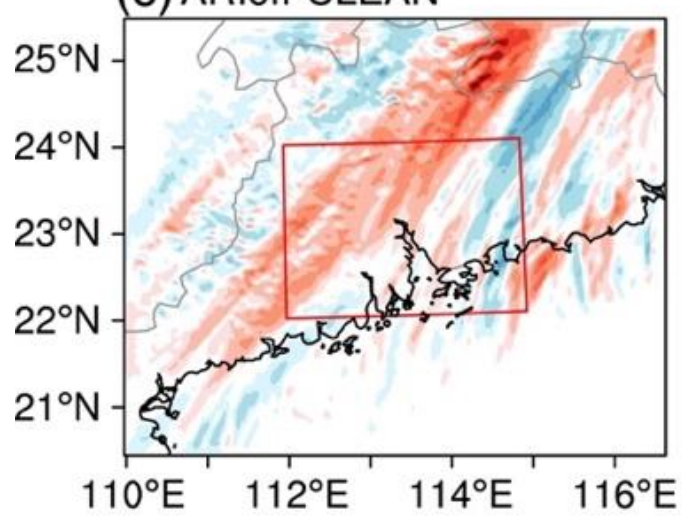

(d) D1-CLEAN

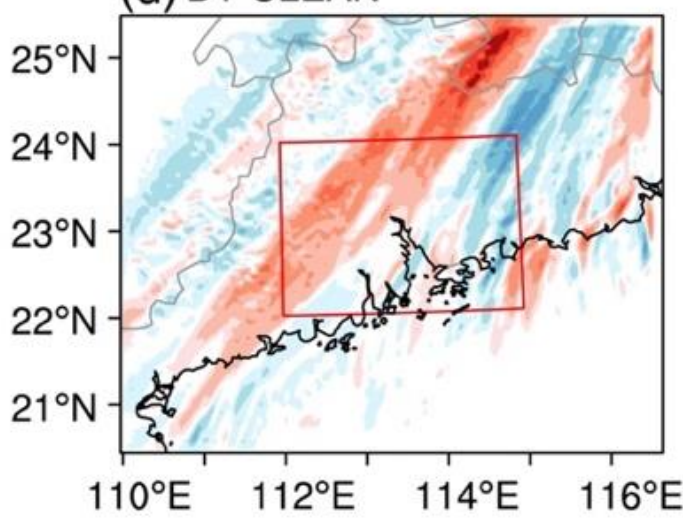

(e)D2-CLEAN

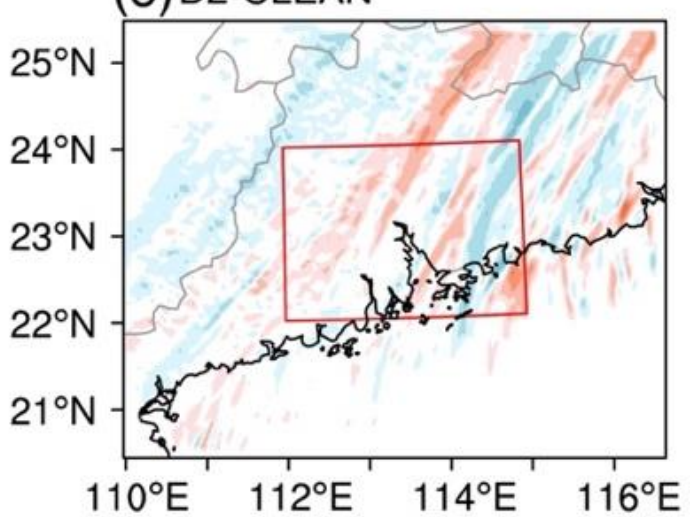

(f) $10 X-C L E A N$

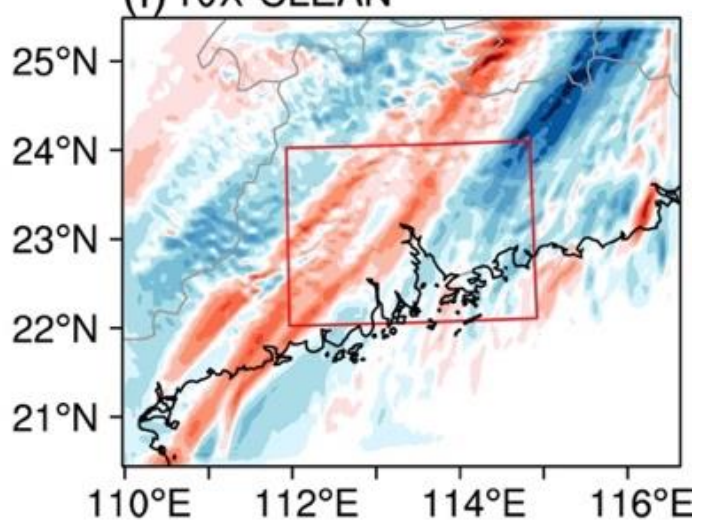

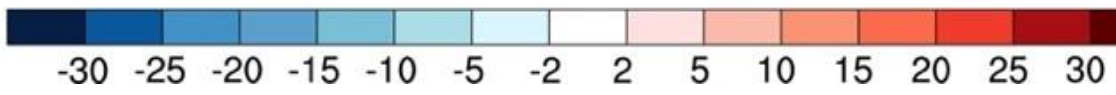

Figure S2. Differences in accumulated precipitation (unit: $\mathbf{m m}$ ) on December 16 between (a) CTL and CLEAN (i.e., CTL minus CLEAN), (b) CTL and ARIoff (i.e., CTL minus ARIoff), (c) ARIoff and CLEAN (i.e., ARIoff minus CLEAN), (d) D1 and CLEAN (i.e., D1 minus CLEAN), (e) D2 and CLEAN (D2 minus CLEAN), and (f) 10X and CLEAN (10X minus CLEAN). Red boxes (22 ${ }^{\circ}-$ $\left.524^{\circ} \mathrm{N}, \mathbf{1 1 2}^{\circ}-115^{\circ} \mathrm{E}\right)$ denote the analysis region. ARIoff run refers to simulation with aerosol-radiation interactions off. 


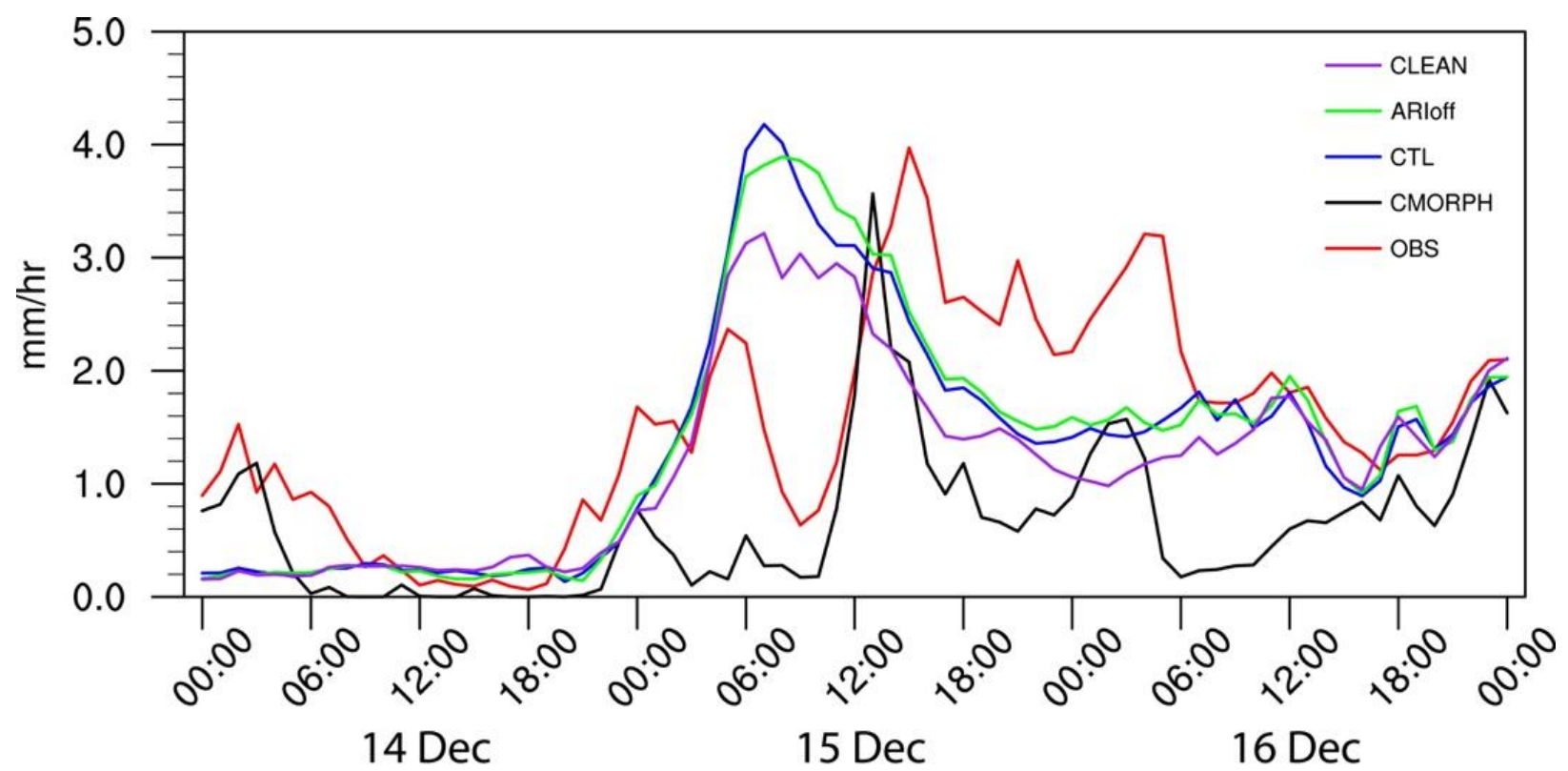

Figure S3. Time series of station average rain rate (unit: $\mathrm{mm} \mathrm{h}^{-1}$ ) over $22^{\circ}-24^{\circ} \mathrm{N}, 112^{\circ}-115^{\circ} \mathrm{E}$ (a) for OBS (red), $\mathrm{CMORPH}(\mathrm{black})$, 5 CTL (blue), ARIoff (green), and CLEAN (purple). 